\title{
Circadian Rhythm Sleep Disorder in Alzheimer's Disease-A consideration in relation with the Neuropathological and Neuroendocrinal alternation-
}

\author{
Miki Umetsu ${ }^{1}$, Kentaro Fukumoto ${ }^{1^{\star}}$, Shigeru Sakurai ${ }^{2}$ and Akio Sakai ${ }^{1}$ \\ ${ }^{1}$ Department of Neuropsychiatry, School of Medicine, Iwate Medical University, Iwate, Japan \\ ${ }^{2}$ Division of Behavioral Sleep Medicine, School of Medicine, Iwate Medical University, Iwate, Japan
}

"Corresponding author: Kentaro Fukumoto, Department of Neuropsychiatry, School of Medicine, Iwate Medical University, 19-1, Uchimaru, Morioka, Iwate, 020-8505, Japan, Tel: +81 19-651-5111; Fax: +81 19-626-4807; E-mail: fukumoto@iwate-med.ac.jp

Received date: Apr 03, 2014, Accepted date: May 19, 2014, Published date: May 25, 2014

Copyright: (C) 2014, Umetsu M et al. This is an open-access article distributed under the terms of the Creative Commons Attribution License, which permits unrestricted use, distribution, and reproduction in any medium, provided the original author and source are credited.

\begin{abstract}
The Circadian rhythm sleep disorder of the dementia is apt to cause night wandering, delirium and even sundowning syndrome. And these behaviors put a major burden on the patients themselves and their caregivers. The ratio of complication of Circadian rhythm sleep disorder in Alzheimer's disease, the major figure of dementia, is considerably high. Circadian rhythm sleep disorder in Alzheimer's disease is supposed to be caused by physiological change of the internal secretion rhythm, physical disorder and/or environmental factors. Furthermore, in recent years, in addition to the high rate of coexistence, it has been reported that there may be essential relation between circadian rhythm sleep disorder and Alzheimer's disease. In the present study, we summarized the role of neuropathological and neuroendocrinal alternation in Circadian rhythm sleep disorder of Alzheimer's disease.
\end{abstract}

Keywords: Alzheimer's disease; Circadian rhythm disorder; Sleep disturbance; Melatonin; Orexin

\section{Introduction}

Dementia is often accompanied by various types of sleep disorders associated with neurotransmission disturbances caused by cortical and subcortical atrophy in different areas, depending on the underlying disease. In Alzheimer's disease (AD), one of the most common causes of dementia, sleep disorder is observed in about $28 \%$ of the patients [1]; when stratified by severity, it is observed in about $25 \%$ of those with mild to moderate $\mathrm{AD}$ and in $50 \%$ of those with severe $\mathrm{AD}$. When compared with normal elderly subjects, the main sleep of AD patients is characterized by intermittent sleep (increased frequency and wake duration after sleep onset (WASO)) and a decrease in deep sleep and REM sleep [2,3]. Also observed are an increased ratio of daytime sleep relative to the total daily sleep duration and increased percentage of deep sleep and REM sleep in the daytime nap [4]. Such increased variability in the circadian rhythm is characteristically observed in $\mathrm{AD}$ patients. The altered circadian rhythm in $\mathrm{AD}$ is associated with a substantial shallowing and/or fragmentation of the sleep structure, characterized by a significant change in the rhythm phase (the duration from hypnagogic state to wakefulness) and a decrease in rhythm amplitude (the strength of the sleep/wake rhythm). By the accommodation disorder of the biological clock (Circadian rhythm), the sleep disorders which cannot sleep at the time when oneself or society wanted are said the Circadian Rhythm Sleep Disorder (CRSD).CRSD in AD patients progresses with increasing disease stage [5] and it is also associated with poor quality sleep, daytime hypersomnia, night delirium, and sundowning syndrome, a condition characterized by excitement occurring in the evening hours [6]. These abnormal behaviors and the associated nighttime insomnia, wandering behavior and excitement render increased stress for caregivers and hamper the provision of home care services, which has become an issue of public concern. This article reviews the characteristics of and treatments for CRSD in $\mathrm{AD}$ patients.

\section{Discussion}

\section{Association of AD and sleep disorders}

Attention has been paid to the possible association between amyloid-beta $(A \beta)$ protein and sleep in $A D$ patients. $A \beta$ level and tau level in cerebrospinal fluid correlates with the Alzheimer's disease onset $[7,8]$. Ju et al. studied the relationship between the quality of sleep as measured by actigraphy and $A \beta 42$ concentration in cerebrospinal fluid in 145 patients aged 45 years or more with normal cognitive function; they reported that $A \beta$ deposition was detected in $22.5 \%$ of all patients and those with $A \beta$ deposition had significantly lower sleep efficiency than those without $A \beta$ deposition [9]. The relationship between CRSD and $A \beta$ has also been studied in animal models. In 3xTg-AD mice, a mouse model of $\mathrm{AD}$ engineered to express amyloid precursor protein (APP) with mutations in the presenilin 1 (Psen1) gene and to express tau protein, circadian rhythm disorder is observed even before the appearance of brain $A \beta$ protein and neurofibrillary tangles [10]. In APPswe/PS1 $\sigma \mathrm{E} 9$ mice, another mouse model of $\mathrm{AD}$ showing abnormal $\mathrm{A} \beta$ production due to APP expression and Psen 1 gene mutations, the sleep/wake rhythm cycle, which was normal in the absence of $A \beta$ plaque formation, was severely disturbed after $A \beta$ plaque formation [11]. It has also been suggested that the REM sleep deprivation is associated with tau accumulation [12]. Thus, the relationship between $A \beta$ accumulation and the development and progression of sleep disorder is suggested to be mutually.

The suprachiasmatic nucleus (SCN) is an important brain region associated with CRSD. The SCN is a known circadian pacemaker in mammals, including humans. Stephan and Zucker have demonstrated that the focal destruction of the SCN results in the loss of circadian rhythm [13]. The number of cells in the SCN decreases with increasing 
age, which is particularly evident in the elderly. Moreover, this decreased cell number in the SCN is more profound in $\mathrm{AD}$ patients than in normal elderly subjects [14]. About half of the cells in the SCN express arginine-vasopressin (AVP) and also its receptors, V1a and $\mathrm{V} 1 \mathrm{~b}$, indicating that an inter-cellular local neural network is formed in the SCN that controls the circadian rhythm [15]. AVP mRNA expression is significantly decreased in AD patients, down to one-third of that in normal elderly [16]. Studies have also shown that the periodic change in the gene expression of vasoactive intestinal peptide (VIP) in the SCN, which is in accordance with the light-dark cycle, is involved in circadian rhythm formation and that this periodic change is lost in elderly rats [17]. In humans, a decrease in the number of VIPexpressing neurons in the SCN has also been detected in both males (in the normal aging process) and females (in AD patients) [18]. These reports suggest the important role of SCN in the development of CRSD in $\mathrm{AD}$ patients.

Orexin, a regulator of the sleep/wake rhythm, has been suggested to be involved in the development of $\mathrm{AD}$. Orexin, which is a neuropeptide specifically expressed by neurons in the lateral hypothalamic area, is known to have various functions, such as the regulation of sleep/wake rhythm, eating behavior, locomotor activity and the autonomic nervous system. The axons of orexin-producing neurons are projected to the entire central nervous system, with the exception of the cerebellum. In the hypothalamus, these axons are projected to nuclei associated with eating behavior, such as the arcuate nucleus and ventromedial nucleus. Outside the hypothalamus, they are densely projected to the locus ceruleus, raphe nucleus (origin of monoaminergic neurons), tuberomammillary nucleus (origin of histaminergic neurons), lateral dorsal tegmental nucleus and pedunculopontine tegmental nucleus (origins of cholinergic neurons).

Monoaminergic and histaminergic neurons are known to be most active during waking, less active during non-REM sleep, and almost silent during REM sleep [19]. These neurons are also projected to the thalamus and cerebral cortex, and a role in the maintenance of arousal. Cholinergic neurons are divided into two types: those activated during waking and REM sleep and those activated only during REM sleep [19]. These facts suggest a physiological role for orexin in the stabilization of the sleep and wake stages. A study using post-mortem brains showed a decreased number of orexin-expressing cells in $\mathrm{AD}$ patients and a decreased orexin level in cerebrospinal fluid [20]. Kang et al. demonstrated that orexin stimulates $A \beta$ accumulation in brain interstitial fluid (ISF) in mice expressing human APP [21]. Furthermore, this study suggested that the amount of ISF A $\beta$ significantly increased during acute sleep deprivation and during orexin infusion, but decreased with infusion of a dual orexin receptor antagonist. These studies suggest the possibility that orexin and the sleep disorders are connected with the AD onset.

Melatonin, a hormone secreted by the pineal gland, is known to have a sleep-promoting effect and a core body temperature-lowering effect [22]. In normal individuals, melatonin secretion is decreased during the day, rapidly increased during the night and reaches its peak during night sleep. Melatonin induces sleep by acting on the SCN and melatonin receptors expressed throughout the body. The blood melatonin level gradually decreases during the night with age and this decrease is more profound in the elderly [23]. In AD patients, a decreased melatonin level compared with normal elderly subjects is observed in the cerebrospinal fluid, as well as in the blood [24-26]. Melatonin is known to penetrate the brain-blood barrier and function as an antioxidant and a free radical scavenger. In $\mathrm{AD}$ patients, a decreased melatonin level leads to greater accumulation of oxidative stress compared to normal elderly subjects [27]. This is supported by a study using a mouse model of $\mathrm{AD}$, where the accumulation of oxidative stress led to increased $A \beta$ deposition [28]. It has also been demonstrated that treating 3xTG-AD mice with melatonin results in reduced $A \beta$ deposition and reduced tau hyperphosphorylation [29]. An in vitro study has also demonstrated that melatonin prevents $A \beta \beta$ sheet formation and $A \beta$ fiber formation [30]. These findings indicate that melatonin is deeply involved in the development of $\mathrm{AD}$ and suggest the beneficial role of its antioxidative and neuro-protective effects in the prevention and treatment of $\mathrm{AD}$.

\section{Therapy of sleep disorders in AD patients}

For the treatment of CRSD in AD patients? For the treatment of CRSD in AD patients, no well-established drug therapy is currently available [31] and non-drug therapy is recommended as the first choice of treatment. CRSD in AD patients is usually treated in the same way as for sleep disorder in the elderly; the aim is to promote good sleep during the night and maintain daytime activity levels.

The most important non-drug therapy is sleep hygiene therapy (SHT). The recommended SHT procedures for $\mathrm{AD}$ patients are available on the Alzheimer's association website [32]. In addition to these therapies, the provisions of correct knowledge about sleep and cognitive therapy for reducing excessive anxiety over insomnia are also recommended. Especially in patients with advanced dementia, for whom recording precise activity levels is often difficult, it may be helpful to present objective measures of activity levels, such as actigraphy data, so that they can realize the discrepancy between selfrated and objectively measured activity levels. For circadian rhythm disorder, the effectiveness of bright light therapy (BLT) has been suggested. BLT aims to improve sleep disorder by changing the phases of circadian rhythm by irradiating high-intensity light of 2500-10000 lux for 30 to 120 minutes during a certain time frame of the day. This therapy is also used for treating primary insomnia in the elderly, who exhibit physiological age-related changes in circadian rhythm, such as attenuation, advanced phase and impaired synchronization [33-36]. For dementia patients with sleep/wake disorder, high-intensity light irradiation given in the morning after getting up can reduce night insomnia, daytime sleepiness and abnormal behaviors, such as delirium. In terms of the effect of BLT on plasma melatonin level in $\mathrm{AD}$ patients, a 4-week treatment with morning BLT has been shown to increase the amplitude of melatonin secretion rhythm in patients with mild AD [37]. Despite these findings, no consensus has been reached regarding the efficacy of BLT in treating circadian rhythm disorder in $\mathrm{AD}$ patients $[38,39]$.

As for drug therapy, the benzodiazepines (BDZs) and Z-drugs (zopiclone, zolpidem and zaleplon) commonly used for treating insomnia are not very effective against sleep disorder in dementia patients, and there is a relatively high incidence of adverse effects. A possible reason for the limited effectiveness of regular hypnotics is because these drugs usually exert sedative/hypnotic actions a few hours after dosing and thus have a minimal effect on improving circadian rhythm. In terms of adverse effects, these drugs have been shown to have increase in the risk of fall in elderly patients with dementia compared to normal elderly subjects [40,41]. Z-drugs hypnotics were known to have a relatively low muscle-relaxing effect due to their selective action on the $\omega 1$ receptor. However, the use of the sleeping drug to elderly people should be cautious even if it is Zdrugs. In the elderly, ultra-short-acting or short-acting hypnotics 
should be used at half the adult dose, due to delayed drug metabolism/ elimination in this population.

Based on the aforementioned relationship between $\mathrm{AD}$ and melatonin, the effectiveness of melatonin substitution therapy has been demonstrated in treating sleep disorder associated with CRSD in $\mathrm{AD}[42,43]$. Asayama et al. reported that treatment with melatonin significantly prolonged sleep duration and decreased nighttime activity in AD patients, compared to placebo. In their study, however, no improvement in daytime naps or activity was observed in those treated with melatonin [44]. Meanwhile, other studies have shown that combined melatonin and light therapy was more effective in improving sleep efficiency and nighttime restlessness compared to melatonin alone, without an adverse effect, and that the addition of melatonin to light therapy resulted in reduced nighttime insomnia and daytime sleepiness, which were not improved by light therapy alone. Ramelteon, a melatonin-receptor agonist known to have a hypnotic/ sedative effect, has also been suggested to be effective in improving sleep/wake rhythm [45]. In advanced cases of dementia, however, ramelteon may not exert its full action due to the reduction or loss of melatonin receptors, which are the sites of action of ramelteon [46]. No consensus has been reached regarding the efficacy of ramelteon in $\mathrm{AD}$ patients [47]. Melatonin therapy may be an important option for the prevention and treatment of $\mathrm{AD}$ in the near future.

Investigations are also in progress on the efficacy of orexin antagonists, based on the demonstrated relationship between orexin and AD. Suvorexant, an oral medication that acts at dural receptors (OX1R/OX2R), has been shown to promote sleep without disturbing the normal sleep/wake rhythm [48]. In a RCT of suvorexant in the treatment of insomnia, suvorexant significantly improved sleep efficiency in a dose-dependent manner and was also effective in sleep induction and maintenance $[49,50]$. However, these studies did not include elderly peoples. Further studies are needed including elderly and dementia patients.

Finally, cholinesterase inhibitors (ChEIs), a group of drugs commonly used for the treatment of $\mathrm{AD}$, have been shown to increase REM sleep, but they may also increase dreaming and nightmares during REM sleep especially when taken late at night [51-53]. Since the cholinergic nervous system is an arousal system, ChEIs action exerted during the night may have an adverse effect on sleep [54]. Concerning the effect of ChEIs on polysomnography, a 6-month long-term treatment with a ChEI resulted in increased REM sleep and reduced slow wave during REM sleep, with a 30-minute reduction in total sleep duration and a $10 \%$ reduction in sleep efficiency, although these were insignificant compared to pre-treatment values [55]. When prescribing a ChEI for a dementia patient with a sleep disorder, additional consideration should be given to the dosing time, such as advising to take the medicine after breakfast.

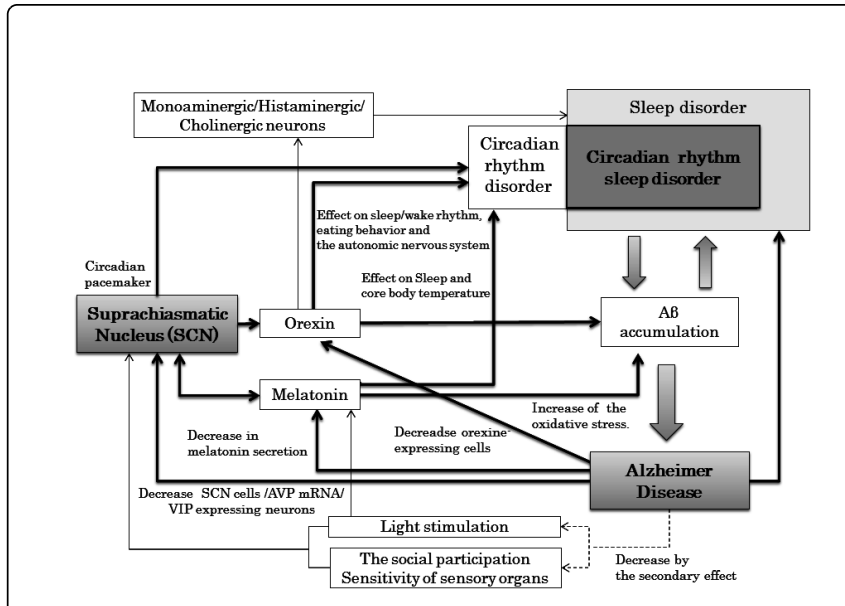

Figure 1: The relationship with the circadian rhythm sleep disorders (CRSD) and Alzheimer's disease (AD)

\section{Conclusion}

CRSD in $\mathrm{AD}$ patients has been associated with $A \beta /$ tau accumulation and endocrine disorders, as mentioned above. Various other factors not referred to in this article, such as reduced social involvement, decreased sensitivity of sensory organs and decreased exposure to environmental light, are also known to impair the circadian rhythm entraining mechanism. Further studies on CRSD in $\mathrm{AD}$ patients will contribute to the early detection and treatment of sleep disorders, as well as the early detection and improved outcome of $\mathrm{AD}$.

\section{References}

1. Tractenberg RE, Singer CM, Kaye JA (2005) Symptoms of sleep disturbance in persons with Alzheimer's disease and normal elderly. J Sleep Res 14: 177-185.

2. Loewenstein RJ, Weingartner H, Gillin JC, Kaye W, Ebert M, et al. (1982) Disturbances of sleep and cognitive functioning in patients with dementia. Neurobiol Aging 3: 371-377.

3. Prinz PN, Vitaliano PP, Vitiello MV, Bokan J, Raskind M, et al. (1982) Sleep, EEG and mental function changes in senile dementia of the Alzheimer's type. Neurobiol Aging 3: 361-370.

4. Vitiello MV, Prinz PN (1990) Sleep/Wake patterns and sleep disoreders in Alzheimer's disease: Handbook of sleep Disorders. Taylor \& Francis press.

5. Mishima K, Okawa M, Satoh K, Shimizu T, Hozumi S, et al. (1997) Different manifestations of circadian rhythms in senile dementia of Alzheimer's type and multi-infarct dementia. Neurobiol Aging 18: 105-109.

6. Simic G, Stanic G, Mladinov M, Jovanov-Milosevic N, Kostovic I, et al. (2009) Does Alzheimer's disease begin in the brainstem? Neuropathol Appl Neurobiol 35: 532-554.

7. Mattsson N, Zetterberg H, Hansson O, Andreasen N, Parnetti L, et al. (2009) CSF biomarkers and incipient Alzheimer disease in patients with mild cognitive impairment. JAMA 302: 385-393.

8. Iliff JJ, Wang M, Liao Y, Plogg BA, Peng W, et al. (2012) A paravascular pathway facilitates CSF flow through the brain parenchyma and the clearance of interstitial solutes, including amyloid $\hat{\mathrm{I}}^{2}$. Sci Transl Med 4: $147 \mathrm{ra111.}$ 
9. Ju YE, McLeland JS, Toedebusch CD, Xiong C, Fagan AM, et al. (2013) Sleep quality and preclinical Alzheimer disease. JAMA Neurol 70: 587-593.

10. Sterniczuk R, Dyck RH, Laferla FM, Antle MC (2010) Characterization of the 3xTg-AD mouse model of Alzheimer's disease: part 1.circadian changes. Brain Res 1348: 139-148.

11. Roh JH, Huang Y, Bero AW, Kasten T, Stewart FR, et al. (2012) Disruption of the sleep-wake cycle and diurnal fluctuation of $\hat{\mathrm{I}}^{2}$-amyloid in mice with Alzheimer's disease pathology. Sci Transl Med 4: 150ra122.

12. Rodríguez-Vázquez J, Camacho-Arroyo I, Velázquez-Moctezuma J (2012) Differential impact of REM sleep deprivation on cytoskeletal proteins of brain regions involved in sleep regulation. Neuropsychobiology 65: 161-167.

13. Stephan FK, Zucker I (1972) Circadian rhythms in drinking behavior and locomotor activity of rats are eliminated by hypothalamic lesions. Proc Natl Acad Sci U S A 69: 1583-1586.

14. Swaab DF, Fliers E, Partiman TS (1985) The suprachiasmatic nucleus of the human brain in relation to sex, age and senile dementia. Brain Res 342: 37-44.

15. Yamaguchi Y, Suzuki T, Mizoro Y, Kori H, Okada K, et al. (2013) Mice genetically deficient in vasopressin $\mathrm{V} 1 \mathrm{a}$ and $\mathrm{V} 1 \mathrm{~b}$ receptors are resistant to jet lag. Science 342: 85-90

16. Liu RY, Zhou JN, Hoogendijk WJ, van Heerikhuize J, Kamphorst W, et al. (2000) Decreased vasopressin gene expression in the biological clock of Alzheimer disease patients with and without depression. J Neuropathol Exp Neurol 59: 314-322.

17. Kawakami F, Okamura H, Tamada Y, Maebayashi Y, Fukui K, et al. (1997) Loss of day-night differences in VIP mRNA levels in the suprachiasmatic nucleus of aged rats. Neurosci Lett 222: 99-102.

18. Zhou JN, Hofman MA, Swaab DF (1995) VIP neurons in the human SCN in relation to sex, age, and Alzheimer's disease. Neurobiol Aging 16: 571-576.

19. España RA, Scammell TE (2004) Sleep neurobiology for the clinician. Sleep 27: 811-820.

20. Fronczek R, van Geest S, Frölich M, Overeem S, Roelandse FW, et al. (2012) Hypocretin (orexin) loss in Alzheimer's disease. Neurobiol Aging 33: $1642-1650$.

21. Kang JE, Lim MM, Bateman RJ, Lee JJ, Smyth LP, et al. (2009) Amyloidbeta dynamics are regulated by orexin and the sleep-wake cycle. Science 326: 1005-1007.

22. Kräuchi K, Cajochen C, Pache M, Flammer J, Wirz-Justice A (2006) Thermoregulatory effects of melatonin in relation to sleepiness. Chronobiol Int 23: 475-484.

23. Karasek M (2007) Does melatonin play a role in aging processes? J Physiol Pharmacol 58 Suppl 6: 105-113.

24. Mishima K, Tozawa T, Satoh K, Matsumoto Y, Hishikawa Y, et al. (1999) Melatonin secretion rhythm disorders in patients with senile dementia of Alzheimer's type with disturbed sleep-waking. Biol Psychiatry 45 417-421.

25. Liu RY, Zhou JN, van Heerikhuize J, Hofman MA, Swaab DF (1999) Decreased melatonin levels in postmortem cerebrospinal fluid in relation to aging, Alzheimer's disease, and apolipoprotein E-epsilon4/4 genotype. J Clin Endocrinol Metab 84: 323-327.

26. Ohashi Y, Okamoto N, Uchida K, Iyo M, Mori N, et al. (1999) Daily rhythm of serum melatonin levels and effect of light exposure in patients with dementia of the Alzheimer's type. Biol Psychiatry 45: 1646-1652.

27. Ozcankaya R, Delibas N (2002) Malondialdehyde, superoxide dismutase, melatonin, iron, copper, and zinc blood concentrations in patients with Alzheimer disease: cross-sectional study. Croat Med J 43: 28-32.

28. Apelt J, Bigl M, Wunderlich P, Schliebs R (2004) Aging-related increase in oxidative stress correlates with developmental pattern of beta-secretase activity and beta-amyloid plaque formation in transgenic Tg2576 mice with Alzheimer-like pathology. Int J Dev Neurosci 22: 475-484.
29. García-Mesa Y, Giménez-Llort L, López LC, Venegas C, Cristòfol R, et al. (2012) Melatonin plus physical exercise are highly neuroprotective in the 3xTg-AD mouse. Neurobiol Aging 33: 1124.

30. Pappolla M, Bozner P, Soto C, Shao H, Robakis NK, et al. (1998) Inhibition of Alzheimer beta-fibrillogenesis by melatonin. J Biol Chem 273: 7185-7188

31. Salami O, Lyketsos C, Rao V (2011) Treatment of sleep disturbance in Alzheimer's dementia. Int J Geriatr Psychiatry 26: 771-782.

32. https://www.alz.org/alzheimers_disease_10429.asp\%20

33. Campbell SS, Dawson D, Anderson MW (1993) Alleviation of sleep maintenance insomnia with timed exposure to bright light. J Am Geriatr Soc 41: 829-836.

34. Suhner AG, Murphy PJ, Campbell SS (2002) Failure of timed bright light exposure to alleviate age-related sleep maintenance insomnia. J Am Geriatr Soc 50: 617-623.

35. Lack L, Wright H, Kemp K, Gibbon S (2005) The treatment of earlymorning awakening insomnia with 2 evenings of bright light. Sleep 28: 616-623.

36. Kohsaka M, Fukuda N, Kobayashi R, Honma H, Sakakibara S, et al. (2000) Effect of short duration morning bright light in elderly men: sleep structure. Psychiatry Clin Neurosci 54: 367-368.

37. Ito T, Ito R, Okubo $\mathrm{Y}$, Hada $\mathrm{M}$ (2003) Blight Light therapy and melatonin in Alzheimer-type dementia. Clinical Psychiatry 45: 951-958.

38. Forbes D, Culum I, Lischka AR, Morgan DG, Peacock S, et al. (2009) Light therapy for managing cognitive, sleep, functional, behavioural, or psychiatric disturbances in dementia. Cochrane Database Syst Rev : CD003946.

39. Hanford N, Figueiro M (2013) Light therapy and Alzheimer's disease and related dementia: past, present, and future. J Alzheimers Dis 33: 913-922.

40. Tinetti ME, Speechley M, Ginter SF (1988) Risk factors for falls among elderly persons living in the community. N Engl J Med 319: 1701-1707.

41. Avidan AY, Fries BE, James ML, Szafara KL, Wright GT, et al. (2005) Insomnia and hypnotic use, recorded in the minimum data set, as predictors of falls and hip fractures in Michigan nursing homes. J Am Geriatr Soc 53: 955-962.

42. Zhdanova IV, Wurtman RJ, Regan MM, Taylor JA, Shi JP, et al. (2001) Melatonin treatment for age-related insomnia. J Clin Endocrinol Metab 86: $4727-4730$.

43. Jean-Louis G, Zizi F, von Gizycki H, Taub H (1998) Effects of melatonin in two individuals with Alzheimer's disease. Percept Mot Skills 87: 331-339.

44. Asayama K, Yamadera H, Ito T, Suzuki H, Kudo Y, et al. (2003) Double blind study of melatonin effects on the sleep-wake rhythm, cognitive and non-cognitive functions in Alzheimer type dementia. J Nippon Med Sch 70: 334-341

45. Dowling GA, Burr RL, Van Someren EJ, Hubbard EM, Luxenberg JS, et al. (2008) Melatonin and bright-light treatment for rest-activity disruption in institutionalized patients with Alzheimer's disease. J Am Geriatr Soc 56: 239-246.

46. Wu YH, Zhou JN, Van Heerikhuize J, Jockers R, Swaab DF (2007) Decreased MT1 melatonin receptor expression in the suprachiasmatic nucleus in aging and Alzheimer's disease. Neurobiol Aging 28: 1239-1247.

47. Lin L, Huang QX, Yang SS, Chu J, Wang JZ, et al. (2013) Melatonin in Alzheimer's disease. Int J Mol Sci 14: 14575-14593.

48. Mould R, Brown J, Marshall FH, Langmead CJ (2014) Binding kinetics differentiates functional antagonism of orexin-2 receptor ligands. $\mathrm{Br} \mathrm{J}$ Pharmacol 171: 351-363.

49. Sun H, Kennedy WP, Wilbraham D, Lewis N, Calder N, et al. (2013) Effects of suvorexant, an orexin receptor antagonist, on sleep parameters as measured by polysomnography in healthy men. Sleep 36: 259-267.

50. Herring WJ, Snyder E, Budd K, Hutzelmann J, Snavely D, et al. (2012) Orexin receptor antagonism for treatment of insomnia: a randomized clinical trial of suvorexant. Neurology 79: 2265-2274. 
Citation: Umetsu M, Fukumoto K, Sakurai S, Sakai A (2014) Circadian Rhythm Sleep Disorder in Alzheimer's Disease-A consideration in relation with the Neuropathological and Neuroendocrinal alternation-. Brain Disord Ther 3: 124. doi:10.4172/2168-975X.1000124

Page 5 of 5

51. Dunn NR, Pearce GL, Shakir SA (2000) Adverse effects associated with the use of donepezil in general practice in England. J Psychopharmacol 14: 406-408.

52. Ross JS, Shua-Haim JR (1998) Aricept-induced nightmares in Alzheimer's disease: 2 case reports. J Am Geriatr Soc 46: 119-120.

53. Yorston GA, Gray R (2000) Hypnopompic hallucinations with donepezil. J Psychopharmacol 14: 303-304.

54. Rogers SL, Doody RS, Mohs RC, Friedhoff LT (1998) Donepezil improves cognition and global function in Alzheimer disease: a 15-week, double-blind, placebo-controlled study. Donepezil Study Group. Arch Intern Med 158: 1021-1031.

55. Moraes Wdos S, Poyares DR, Guilleminault C, Ramos LR, Bertolucci PH, et al. (2006) The effect of donepezil on sleep and REM sleep EEG in patients with Alzheimer disease: a double-blind placebo-controlled study. Sleep 29: 199-205. 